\title{
A educação ambiental através de montagem e simulação de células solares sensibilizadas com corante orgânico
}

\author{
Environmental education through assembly and simulation sensitized solar cells \\ with organic dye
}

\author{
Samuel Gondim Sampaio ${ }^{1}$ e Alexandra de Vasconcelos Feitosa², \\ ${ }^{1}$ Doutorando em Biotecnologia, Universidade Federal do Ceará, Fortaleza/CE, Brasil \\ sam.gs@hotmail.com \\ ${ }^{2}$ Doutoranda em Engenharia Civil, Universidade Federal do Ceará, Fortaleza/CE, Brasil \\ alexandravf@bol.com.br
}

\begin{abstract}
Resumo
Este estudo mostrou como relacionar de forma prática a Educação Ambiental com a energia solar, que não gera resíduos danosos ao meio ambiente e por isso, é considerada limpa. As células solares sensibilizadas com corante são dispositivos que convertem energia solar em energia elétrica e tem atraído grande atenção nas últimas décadas. Essas células são de baixo custo, principalmente quando se utilizam corantes naturais. Com o uso de software livre Scilab 5.5.1 foi possível simular o comportamento elétrico de forma aceitável as células sensibilizadas com corante natural obtido a partir da planta Nerium oleander (oleander) com dois tipos de solventes do extrator. Os resultados das simulações mostraram que o software produziu resultados elétricos que estão de acordo com os resultados experimentais obtidos pelo simulador solar, proporcionando uma forma eficaz de promover a educação ambiental. Os menores erros relativos foram relacionados com o corante extraído com etanol: corrente de curto circuito $(0,004 \%)$, a tensão de circuito aberto $(0,01 \%)$ e o erro relativo de eficiência usando o solvente etanol acidificado foram de 6,67\%. A produção de células solares de baixo custo combinado com a análise por simulação em computador em software livre apresenta-se como uma ferramenta útil que pode ser usado em educação ambiental. É sugerida uma proposta para aulas de laboratório com essa simulação das células solares, onde se mostram as etapas de um miniprojeto sustentável com aplicação residencial.
\end{abstract}

Palavras-chave: Educação Ambiental; Célula solar; Simulação.

\begin{abstract}
This study showed how to relate to practical environmental education with solar energy, which generates no harmful waste to the environment and so it is considered clean. These cells are low cost, particularly when using natural dyes. With the use of free software Scilab 5.5.1 was possible to simulate the electrical behavior of acceptable way the sensitized cells with natural dye obtained from the Nerium oleander plant (oleander) with two types of extractor solvents. The simulation results showed that the software produced electrical results that are in agreement with the experimental results obtained by the solar simulator, providing an effective way to promote environmental education. Smaller relative errors were related to the dye extracted with ethanol: short circuit current $(0.004 \%)$, the open circuit voltage $(0.01 \%)$ and the relative error of efficiency using the solvent acidified ethanol was $6.67 \%$. The production of solar cells of low cost combined with analysis by computer simulation in free software, presents itself as a handy tool that can be used in environmental education. A proposal is suggested for laboratory classes with this simulation of solar cells, which shows the steps of a sustainable mini-project with residential application.
\end{abstract}

Keywords: Environmental education; Solar cell; Simulation. 


\section{Introdução}

As atuais pesquisas sobre energia indicam que as reservas mundiais de combustíveis fósseis, além de não acompanhar a demanda mundial crescentes, serão escassas em apenas algumas décadas. Essas limitações caracterizam os tipos de energia classificadas como não renováveis. Além disso, esse tipo de energia sempre está associado aos problemas ambientais, tais como a poluição, o aquecimento global, as chuvas ácidas e a depleção da camada de ozônio (COSTA, 2011). Assim, torna-se vital o estudo e o desenvolvimento de tecnologias em energias renováveis que causem uma diminuição de poluentes no meio ambiente.

O aproveitamento da luz solar é uma das alternativas mais promissoras para enfrentar os desafios energéticos do novo milênio. $\mathrm{O}$ fornecimento de energia do Sol para a Terra é cerca de 3 x 1024 joules ( 3 x 1018 MJ) por ano, ou seja, cerca de 10.000 vezes mais do que a população global consome atualmente (GRÄTZEL, 2001; FEITOSA, 2011).

O Brasil é um país privilegiado em termos de radiação solar na grande maioria do seu território devido sua posição geográfica. Principalmente na região Nordeste o clima é predominantemente semiárido, com luz solar intermitente durante quase todos os dias do ano (MARTINS et al., 2006; CAVALCANTE, 2015). A Figura 1 ilustra a variação da radiação solar no Brasil.
A energia solar que incide sobre a superfície do planeta pode ser captada por células solares sensibilizadas por corante, conhecidas mundialmente como dye cell ou DSSC (Dye Sensitized Solar Cell ou células solares sensibilizadas com corante CSSC), que foram inicialmente desenvolvidas pelo grupo de pesquisa de Michael Grätzel na Suíça nos anos 90 (O'REAGAN e GRÄTZEL, 1991). As células solares são uma das formas mais promissoras de obtenção de energia renovável a partir do sol. Pesquisar sobre novos protótipos de fácil manuseio e baixo custo é uma vertente nessa pesquisa.

Entretanto, enquanto as Dye Cell podem apresentar um custo relativamente baixo de produção e compra de seus componentes, suas formas de caracterização ainda apresentam um custo elevado visto que simuladores solares chegam a custar milhares de reais. De modo que, pesquisar novas formas de caracterização elétrica de células solares, tal como a simulação computacional, se apresenta como uma estratégia bastante útil para a produção de protótipos cada vez mais eficientes. Isso também contribui para a inserção do conteúdo de energias renováveis na educação ambiental.

De acordo com Effting (2007) a educação ambiental deve propiciar à população uma compreensão crítica e global do ambiente, além de esclarecer valores e desenvolver atitudes que lhes permitam adotar uma posição consciente e participativa do uso dos recursos naturais. Ela é necessária na formação de indivíduos

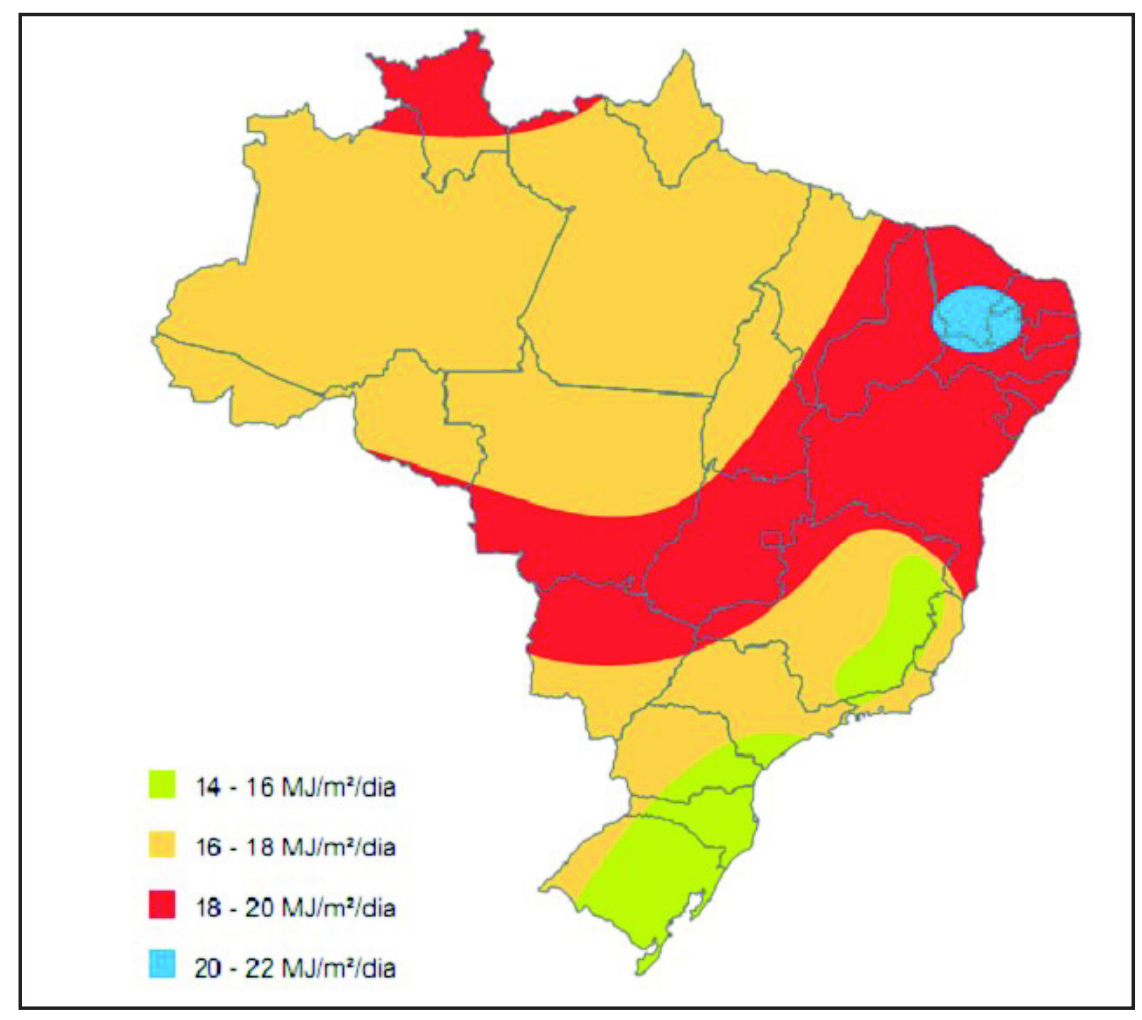

Figura 1 - Variação da Radiação solar no Brasil Fonte: ANEEL (2008); FEITOSA; CAVALCANTE (2015). 
com uma nova perspectiva sobre o meio ambiente que sejam capazes de superar a crise mundial presenciada atualmente (GOMES, 2006).

Os Parâmetros Curriculares Nacionais para o Ensino Médio (PCEM) preconizam um ensino com novas dimensões, promovendo um conhecimento contextualizado e integrado à vida de cada jovem, como as questões referentes ao uso das diferentes fontes de energia em escala social e das células fotoelétricas, das radiações presentes no dia-a-dia, mas também dos princípios gerais que permitem generalizar todas essas compreensões (BRASIL, 2002).

A educação ambiental é um tema tão atual quanto o uso de tecnologias e softwares na educação. Atrelar esses dois conceitos com o estudo de células solares sensibilizadas com extratos de plantas pode trazer a atenção dos alunos a viabilidade do uso das energias renováveis. Assim também, pode chamar atenção para a problemática do desperdício da energia e as suas consequências para o meio ambiente. Além disso, incentiva o cultivo de flores e plantas, como a planta Nerium oleander (espirradeira), o que possibilita um contato maior com a natureza e atividades interdisciplinares. A figura 2 mostra a planta espirradeira.

A Nerium oleander também conhecida como espirradeira, oleandro ou oleandro da índia é uma planta resistente, adaptável e nativa do Himalaia. Suas referências históricas datam do século 15 a.c pelos mesopotâmios, que a utilizavam com propósitos medicinais. Atualmente, os extratos dessa planta são analisados para o tratamento de doenças e a produção de inseticidas naturais (MEDICINAIS 2011). Essa planta possui um alto teor de pigmentos orgânicos (antocianinas) que são capazes de propiciar uma transição eletrônica dentro da célula solar. Ao absorverem fótons de luz de comprimento de onda específico, esses pigmentos iniciam uma reação em cadeia movimentando elétrons (AGNALDO e CRESSONI, 2006).

A literatura relata a atuação de diversas espécies orgânicas como sensibilizadores de células solares. Por exemplo, trabalhos com extratos de amora, framboesa, mirtilo, repolho roxo, malva branca, alamanda entre outros (PATROCÍNIO e ILHA, 2010; SAMPAIO, 2012). Geralmente, é feita uma comparação entre células solares com esses extratos naturais e aquelas que utilizam sensibilizadores inorgânicos feitos com complexos de rutênio Ru (II), que possuem uma eficiência de até 11\%. Entretanto, essas células com extratos naturais, embora com eficiência menor, são mais vantajosas na relação custo-benefício (PATROCÍNIO e ILHA, 2010). A figura 3 mostra um esquema para estudo e a simulação computacional de célula solar sensibilizada com corante extraído de planta dentro de um contexto de educação ambiental.

A simulação de uma célula solar sensibilizada com corante orgânico também pode ser construída como um modelo teórico de um diodo semicondutor, onde se usa valores elétricos obtidos de dados experimentais. Usando este modelo, é possível obter resultados satisfatórios com erros mínimos. Um modelo mais completo pode ser utilizado com a adição de outros diodos em paralelo no modelo proposto (SANTOS 2012).

A simulação computacional está relacionada com a reprodução simplificada de um fenômeno que pode ser complexo, caro ou perigoso (GREIS e REATEGUI, 2010). É um recurso pedagógico interessante porque facilita o processo de ensino e aprendizagem ao passo que promove uma interação homem-máquina. No caso das

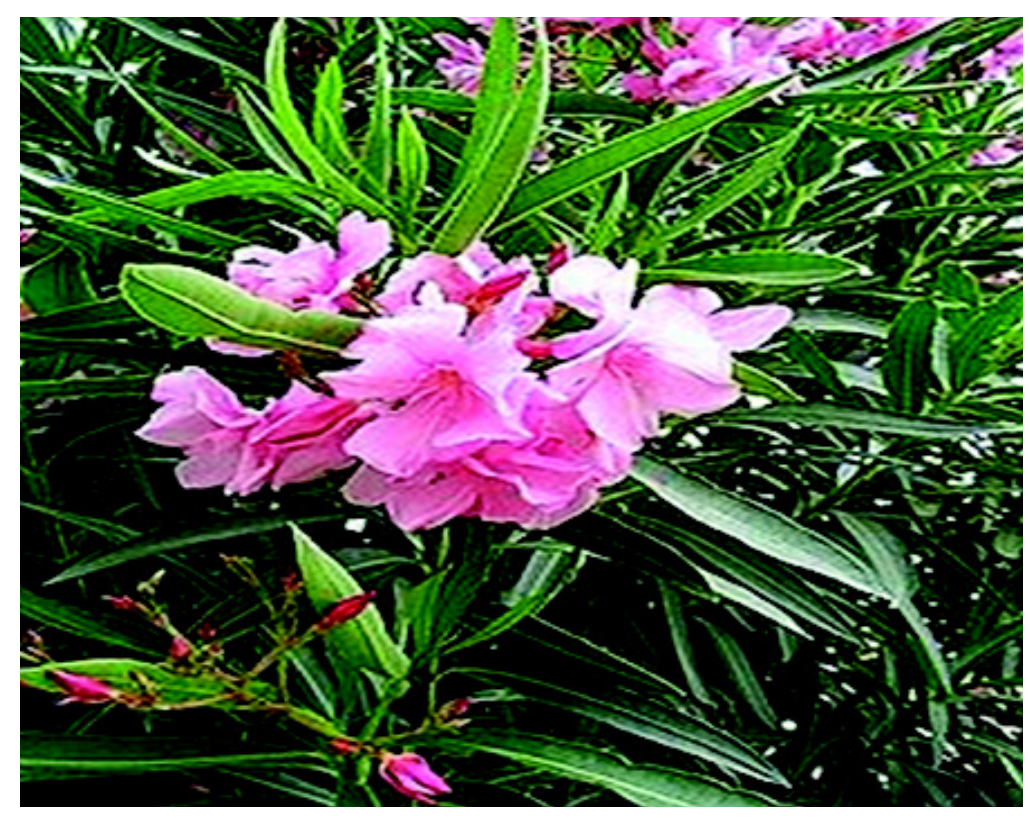

Figura 2- Planta Nerium oleander (espirradeira)

Fonte: MEDICINAIS, 2011. 
células solares, a simulação computacional representa uma diminuição significativa na redução de custos, isso porque os simuladores solares são substituídos por um multímetro simples e um software simulador (GREIS e REATEGUI, 2010). A figura 3 mostra um modelo de esquema de estudo para a introdução do conceito de simulação computacional de célula solar sensibilizada com corante extraído de plantas na Educação Ambiental. Esse exemplo sugere que se introduza conceitos de sustentabilidade, onde se pode falar da necessidade de

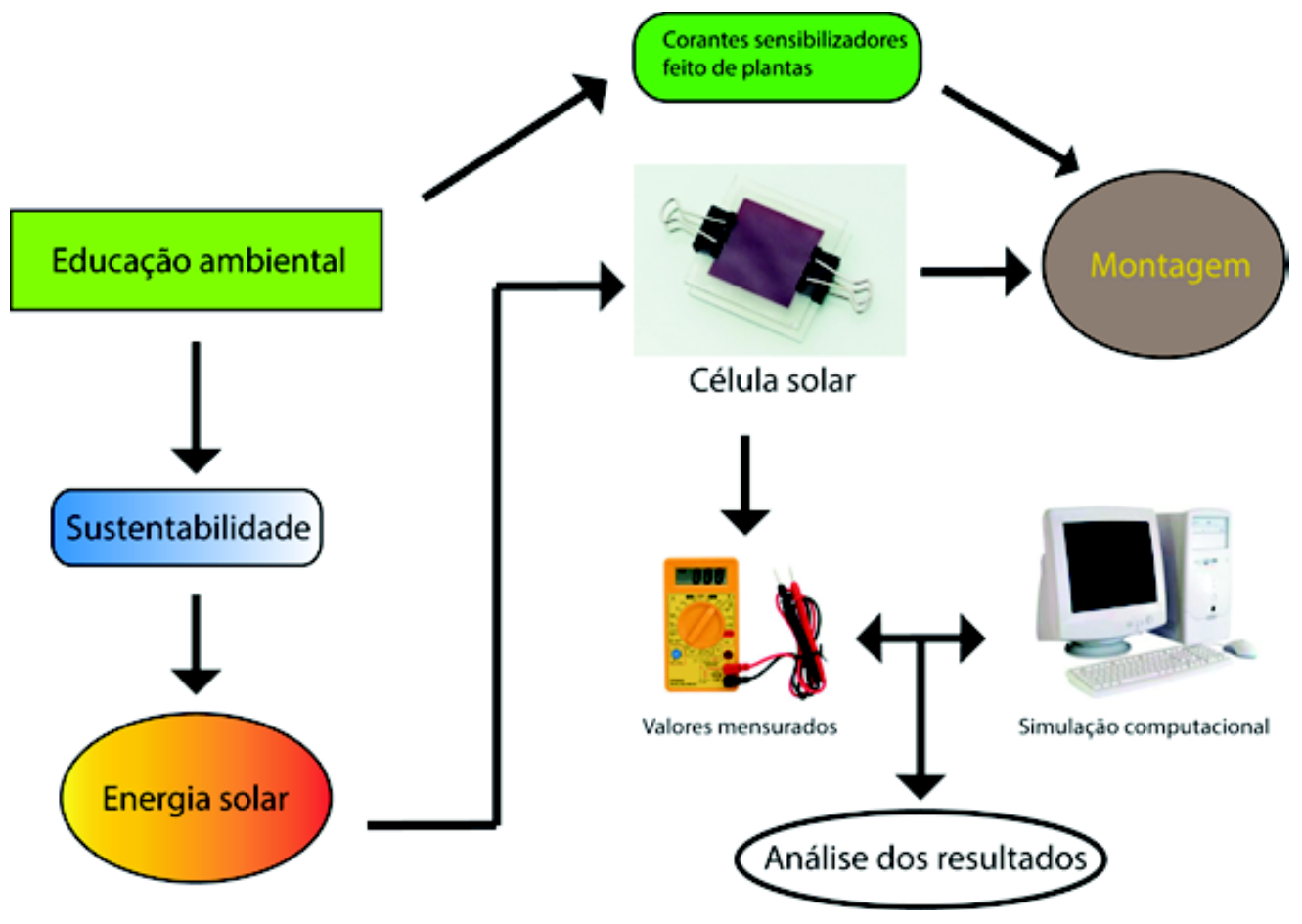

Figura 3 - Esquema para a metodologia proposta

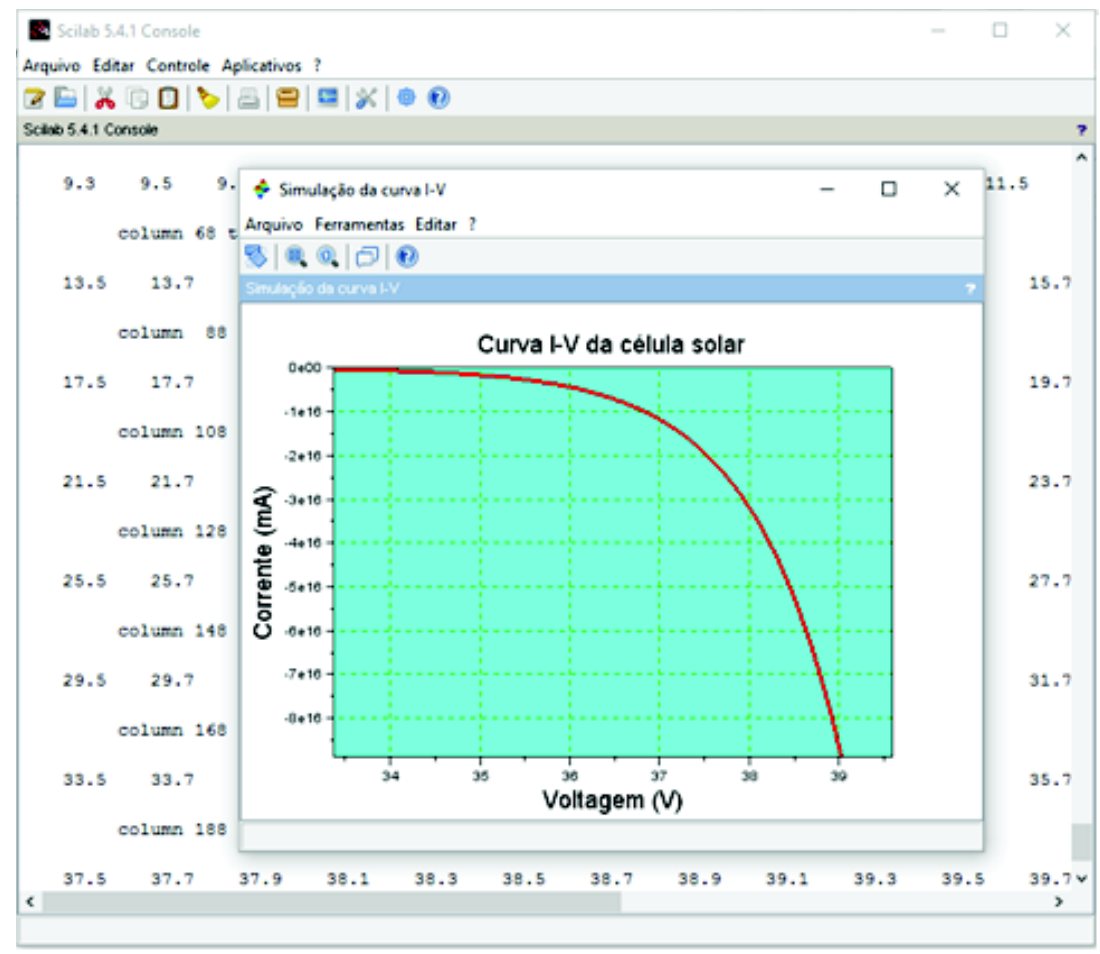

Figura 4- Exemplo de simulação da curva I-V no software Scilab Fonte: Autor 
diversificar a matriz energética com o uso da energia solar. Ao abordar a temática da energia solar e suas várias vantagens, é mostrado como as células solares podem ter um papel fundamental nesse processo. Nesse contexto, as células solares sensibilizadas com corante orgânico extraído de plantas entram como uma possibilidade vantajosa por terem baixo custo de fabricação e fácil manuseio. Os valores elétricos, como corrente (I) e tensão (V), desse tipo de célula são mensurados e introduzidos no software simulador para a resolução da equação da célula solar (equação de diodo), o gráfico característico da curva I-V é plotado e são feitas análises dos resultados.

As maiorias das simulações computacionais são feitas em softwares de cunho comercial, com poucos gratuitos. O Scilab é um software gratuito de código aberto desenvolvido desde 1990 pelos pesquisadores do INRI/ENPC (Institut National de Reacherche en Informatique et em Automatique/École Nationale des Ponts et Chaussées) e mantido desde 2012 pela Scilab Enterprises que pode ser empregado na simulação de célula solar.

O software Scilab é um "open source" capaz de resolver equações diferenciais, integrais entre outras. Apresenta uma estrutura simples e de fácil manuseio, características interessantes que podem propiciar a pesquisa e resolução dos modelos físicos das células solares. A Figura 2 apresenta uma célula sensibilizada por corante após sua montagem e o exemplo de uma simulação $3 \mathrm{~d}$ feita pelo software.

Nesse trabalho utilizou-se o software Scilab 5.5.1 para simular as caracterizações elétricas de uma célula solar, pois ele é obtido de forma gratuita e de fácil manuseio para utilização no ensino médio. Com esse software foi obtida a curva I-V para a célula solar sensibilizada com corante orgânico com dois solventes extratores e comparado com um simulador solar comercial com o objetivo de verificar as principais características elétricas do dispositivo fotovoltaico. Após isso, são dadas sugestões de como utilizar esse experimento para trabalhar conceitos da Educação Ambiental em sala de aula.

\section{Materiais e método}

\section{Montagem da célula}

A montagem da célula solar sensibilizada com corante orgânico foi utilizado o procedimento segundo a literatura (SILVA, 2004; GRATZEL, 2004). Para obtenção do corante natural foram utilizadas as pétalas das plantas Nerium oleander. As amostras foram pesadas e maceradas no solvente, utilizando a proporção de 1:4 $(\mathrm{m} / \mathrm{v})$. O material permaneceu no solvente etanol e etanol acidificado com ácido clorídrico $(\mathrm{PH}=2)$ por $24 \mathrm{~h}$, envolto no papel alumínio sob-refrigeração $\left(5,0 \pm 1,0^{\circ} \mathrm{C}\right)$ e após esse período o material foi filtrado (HAO, 2005; SAMPAIO, 2013).

O extrato foi armazenado em um frasco âmbar, para evitar a degradação pela ação da luz, e foi mantido sob -refrigeração $\left(5,0 \pm 1,0^{\circ} \mathrm{C}\right)(\mathrm{CHANG}, 2010)$. Em todos os experimentos, os filmes de $\mathrm{TiO} 2$ foram depositados em substrato de vidro condutor recobertos com película de $\mathrm{SnO} 2(70 \Omega / \mathrm{cm} 2)$ (GHENSEV, 2006). Os substratos foram previamente limpos utilizando os seguintes solventes: éter de petróleo, acetona e álcool isopropílico, respectivamente. Esses substratos foram mantidos imersos por 1 min em banho de ultrassom em cada solvente.

Os filmes foram preparados pela técnica de silk screen a partir da pasta de $\mathrm{TiO} 2$ preparada utilizando pó de TiO2 (P-25 DEGUSSA), etil celulose, etanol e triton X-100 para melhorar a aderência do filme com o substrato condutor (YAMAZAKI, 2007). O etil celulose tem a função de aumentar a viscosidade da emulsão. A dispersão é ultrassonificada por $30 \mathrm{~min}$. No processo de deposição foi utilizada uma tela serigráfica de poliéster, $35 \times 25 \mathrm{~cm}$, contendo 165 fios por centímetro quadrado.

Foram depositadas, manualmente, quatro camadas da solução pastosa de $\mathrm{TiO} 2$ sobre o substrato condutor de dimensões $2,6 \mathrm{~cm} \times 2,0 \mathrm{~cm}$. Após a deposição, os filmes foram sintetizados até $450^{\circ} \mathrm{C}\left( \pm 7,0^{\circ} \mathrm{C}\right)$ em forno mufla micro processado e permanecendo nesta temperatura por $30 \mathrm{~min}$. Com esse tratamento, as partículas do óxido se fixam sobre o substrato (NOGUEIRA, 2001).

O eletrólito líquido foi preparado a partir de uma mistura de duas soluções (BALRAJU, 2009): $1 \mathrm{M}$ de iodeto de potássio (KI) com 0,1 M iodo re-sublimado (I2), cujo solvente usado foi etileno glicol. $\mathrm{O}$ pH da solução resultante foi 5 e o eletrólito possui coloração vermelho intenso de aspecto viscoso (NOGUEIRA, 2001).

Para a sensibilização do eletrodo de $\mathrm{TiO} 2$, inicialmente o filme é aquecido a $70^{\circ} \mathrm{C}$ por $30 \mathrm{~min}$ para a retirada da umidade do filme. A seguir, ele foi imerso no corante por $2 \mathrm{~h}$. Posteriormente o excesso do corante foi retirado com água destilada e álcool etílico (FEITOSA, 2011).

As células foram montadas em uma cuba de teflon composta por dois eletrodos de área ativa de 1,0 cm2, onde o eletrodo de trabalho é o eletrodo de $\mathrm{TiO} 2$ e o eletrodo de referência é o contra eletrodo formado por uma chapa de platina (SAELIM, 2011; FEITOSA, 2011). Entre os dois eletrodos foi injetado o eletrólito líquido, formando um dispositivo de arquitetura tipo sanduíche.

Entre as propriedades fotovoltaicas das células solares foram determinadas como a densidade de corrente de curto circuito (Jsc, $\mathrm{mA} / \mathrm{cm} 2$ ), voltagem de circuito aberto (Vca, $\mathrm{mV})$, fator de forma (FF), e eficiência ( $\eta, \%)$. Esses dados foram obtidos usando um potenciostato da Microquímica, sendo a célula iluminada com uma lâmpada de irradiação A.M 1.5 sob uma irradiação de luz branca de $1000 \mathrm{~W} / \mathrm{m} 2$ e a área útil da célula iluminada de foi de $1,0 \mathrm{~cm} 2$. Os dados coletados foram comparados com a simulação e analisados de forma analítica e gráfica.

\section{Processo de simulação}

As simulações das resoluções do modelo matemático 
Tabela 1 - Principais parâmetros fotovoltaicos da célula solar

\begin{tabular}{|c|c|c|}
\hline Equação característica da célula solar & Potência máx. & Eficiência da célula \\
\hline $\begin{array}{l}\text { Icell: Corrente através da célula } \\
\text { IF: Corrente fotogerada } \\
\text { Is: Corrente de Saturação } \\
\text { Q: Carga do elétron } \\
\text { V: Tensão } \\
\text { Fi: Fator de idealidade } \\
\text { K: Constante de Boltzman } \\
\text { T: Temperatura ambiente }\end{array}$ & $\begin{array}{c}\text { Pmax: } \\
\text { Potência máxima } \\
\text { Imax: } \\
\text { Corrente } \\
\text { máxima } \\
\\
\text { Vmax: } \\
\text { Tensão máxima }\end{array}$ & $\begin{array}{l}\text { ๆ: Eficiência da célula } \\
\text { solar } \\
\text { FF: Fator de forma } \\
\text { Vca: Tensão de circuito } \\
\text { aberto } \\
\text { Icc: Corrente de curto } \\
\text { circuito } \\
\text { A: Área da célula solar } \\
\text { Pinc: Potência } \\
\text { incidente }\end{array}$ \\
\hline
\end{tabular}

foram descritas tal como em Santos (2012, p. 28). Procurou-se focar os pontos mais importantes do modelo, como as correntes elétricas de diodo e paralela. Para isso, foi aproximado alguns valores de modo descrever bem o comportamento da célula solar.

Em um dispositivo fotovoltaico uma resistência natural a passagem de cargas faz surgir uma barreira de potencial proporcional a tensão aplicada. Assim, a corrente que há nas extremidades da conexão é o resultado da subtração dessas duas correntes: a corrente fotogerada e a corrente de recombinação elétron-buraco. De modo que, a célula solar possui os seguintes parâmetros fotovoltaicos, conforme mostra a tabela 1 .

Na primeira coluna há a equação característica que descreve a relação principal entre as correntes elétricas (Icell, If, Is) numa célula solar. Pode-se representar uma célula solar por um circuito com um diodo, por isso um fator de idealidade Fi (aproximado para 1 na simulação), que depende da fabricação do diodo quanto ao tipo de material e a dopagem entre outras características. Assim também, características relativas ao fluxo de carga e diferença de potencial $(Q, V)$ e a sua dependência com a temperatura $(\mathrm{K}, \mathrm{T})$.

Uma relação importante nos dispositivos fotovoltaicos é a produção de uma potência máxima (Pmax) como o produto da corrente máxima (Imax) com a tensão máxima (Vmax.), sendo um parâmetro relevante para a indicação de energia elétrica produzida.

A terceira coluna mostra a equação da eficiência da célula solar (). Nessa há o fator de forma ou fator de preenchimento (FF) que descreve uma diferença entre os parâmetros obtidos com os calculados. Icc é a corrente de curto circuito, ou seja, quando a corrente do dispositivo é a própria corrente fotogerada $(\mathrm{V}=0)$. Nessa condição, se a célula for colocada em uma condição de circuito aberto (I=0), a corrente de polarização vai equilibrar a fotocorrente em um processo de auto polarização. Nesse caso, a tensão é denominada tensão de circuito aberto Vca. Os parâmetros estruturais da área celular e a potência incidente sobre essa área (A, Pinc) são importantes para a obtenção das medidas de forma exata.

A simulação foi feita por utilizar a noção de vetor para representar os valores das células solares. Essa representação foi visualizada no software Scilab.

\section{Resultados e discussão}

A simulação das caracterizações elétricas da célula solar com corante orgânico extraído com etanol planta Nerium oleander está descrita na Tabela 1 . Os valores obtidos no simulador solar usando uma irradiação de $1000 \mathrm{~W} / \mathrm{m} 2$ e temperatura de $27^{\circ} \mathrm{C}$ estão também inseridos com o objetivo de averiguar a validade das simulações feitas no software Scilab 5.5.1 (AMANTÉA, 2014). Embora ambos sejam simuladores, um solar e um computacional com software, foi assinalado como "simulado" apenas os valores que o software Scilab gerou ao resolver o modelo matemático inserido na janela editora SciNotes, onde foi criado e executado um arquivo natural do Scilab de extensão ".sci".

Com a ampliação da imagem dos valores no software Scilab 5.5.1, pode-se visualizar o valor simulado da tensão de circuito aberto com um erro relativo de centésimos de percentual. Assim também, a corrente de curto circuito simulada no software obteve um erro relativo mínimo na casa de milésimos de percentual. Esses valores de erros relativos se encontram dentro de valores esperados 
Tabela 1- Caracterização elétrica e simulação da célula solar

\begin{tabular}{c|c|c|c|c|c|c}
\hline Planta & Solvente extrator & $\begin{array}{c}\text { Icc (MA/ } \\
\mathrm{cm} 2)\end{array}$ & Vca (V) & Pmáx (mWcm-2) & FF & $\eta(\%)$ \\
\hline $\begin{array}{c}\text { Nerium } \\
\text { oleander }\end{array}$ & Etanol & 0,24 & 0,39 & 0,04 & 0,42 & 0,041 \\
\hline Valor simulado & Etanol & 0,24001 & 0,39004 & 0,046 & 0,49 & 0,046 \\
\hline $\begin{array}{c}\text { Erro Relativo } \\
(\%)\end{array}$ & Etanol & 0,004 & 0,01 & 17,00 & 19,00 & 15,00 \\
\hline
\end{tabular}

das medidas reais dos protótipos. De modo que, essa precisão da simulação e o erro relativo mostram que a simulação computacional com o software escolhido é uma ferramenta eficaz na obtenção das características elétricas das células solares sensibilizadas com corante natural de planta extraído com etanol, como mostra a figura 4.

Figura 5- a) I-V da planta Nerium oleander com solvente etanólico b) Simulação da

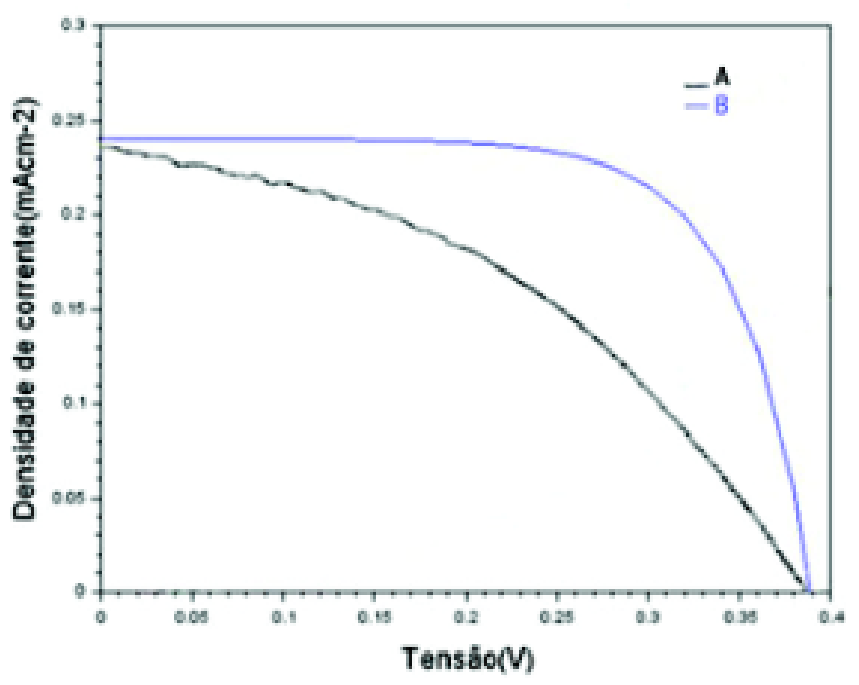

As funções do software no Scilab se mostraram muito úteis para a descrição e análise das propriedades fotovoltaicas da célula solar. A função deff e Function foram usadas para definir a área sobre a curva que define o fator de forma (FF) e gerar o gráfico da potência máxima (Pmáx). (Assim também, a exponencial decrescente que simulou a curva I-V foi gerada pelo comando exp. A função disp foi usada para exibir as variáveis do programa enquanto que a função plot gerou os gráficos da figura 4 b) e $5 b$.

O Fator de Forma (FF) mostra que a qualidade da simulação da célula solar foi mais expressiva que os dados obtidos pelo simulador comercial. Para esta análise foi utilizado o loop ou laço de repetição para postar os maiores valores do produto Icc e Vca a fim de determinar a área sobre a curva.

Devido aos resultados promissores, outro protótipo de célula solar foi testado utilizando um solvente extrator de etanol e ácido clorídrico. Os valores obtidos estão na tabela 2.

Os resultados com o segundo solvente mostraram que algumas características elétricas foram aumentadas enquanto que outras não. Os valores simulados de corrente e tensão tiveram um aumento significativo quando comparados com o primeiro solvente, embora menor que $1 \%$. Esses dados foram usados para plotar a curva da figura 5 .

Tabela 2- Caracterização elétrica e simulação da célula solar com solvente extrator contendo etanol e ácido clorídrico

\begin{tabular}{c|c|c|c|c|c|c}
\hline Planta & Solvente extrator & $\begin{array}{c}\text { Icc (MA/ } \\
\mathrm{cm} 2)\end{array}$ & Vca (V) & $\begin{array}{c}\text { Pmáx } \\
(\mathrm{mWcm}-2)\end{array}$ & FF & $\eta(\%)$ \\
\hline Nerium oleander & $\begin{array}{c}\text { Etanol/ácido } \\
\text { clorídrico }\end{array}$ & 0,21 & 0,38 & 0,03 & 0,43 & 0,03 \\
\hline Valor simulado & $\begin{array}{c}\text { Etanol/ácido } \\
\text { clorídrico }\end{array}$ & 0,209 & 0,381 & 0,032 & 0,40 & 0,032 \\
\hline Erro Relativo (\%) & $\begin{array}{c}\text { Etanol/ácido } \\
\text { clorídrico }\end{array}$ & 0,48 & 0,26 & 6,67 & 6,97 & 6,67 \\
\hline
\end{tabular}




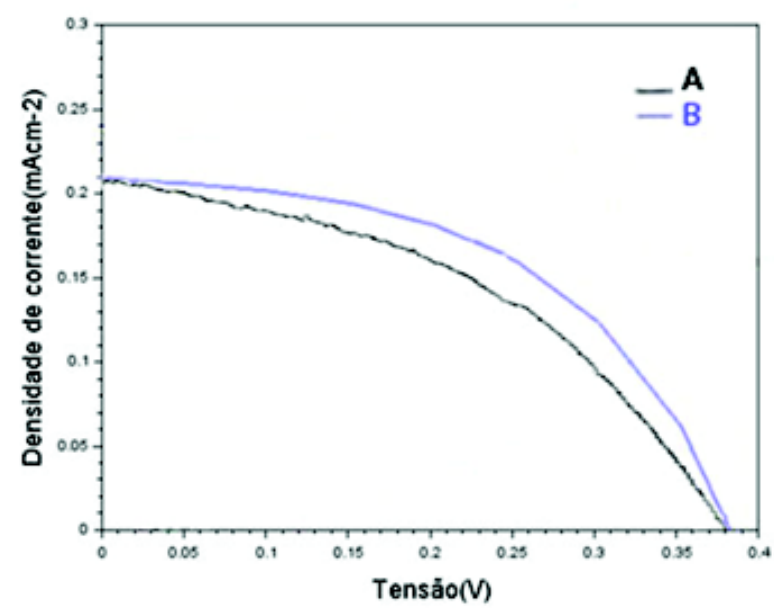

Figura 6 - Curva I-V da célula sensibilizada por corante com solvente etanol/HCl. a) Dados de bancada; b) Simulação.

A partir das análises dos gráficos verificou-se que o desempenho da simulação foi promissor nos dois protótipos. Foi observado que para a corrente de curto circuito, houve erros relativos menores que 0,5\% em ambos os casos. Para as eficiências esses erros relativos não foram maiores que $15 \%$, sendo o segundo protótipo com erro relativo de eficiência menor que $7 \%$. Considerando os valores obtidos, pode-se verificar que os valores simulados se encontram dentro da faixa de valores aceitáveis ao próprio experimento. As descrições computacionais e as aproximações geram gráficos e valores na mesma de grandeza dos valores obtidos em um simulador solar.

Os parâmetros obtidos a partir das curvas da planta Nerium oleander, revelam o melhor desempenho do dispositivo no processo de conversão foi o que utilizou o extrato etanólico, visto que possui maior fotocorrente $(0,24 \mathrm{MA} / \mathrm{cm} 2)$ quando comparada com os demais solventes e também apresentou maior eficiência de conversão (0,04\%). No extrato acidificado, os resultados obtidos são semelhantes. A fotocorrente foi de 0,23 MA/cm2 e a eficiência oi de 0,03\%. Quando se comparam os resultados dos extratos com as simulações observa-se que os extratos da planta Nerium oleander apresenta resultados promissores para aplicação em células solares.

\section{Proposta para sala de aula}

A Educação ambiental deve orientar o uso dos recursos naturais para promover práticas sustentáveis, sendo isso conseguido através de reflexões, discussões e práticas de planejamento. Assim esse trabalho propõe primeiramente um debate sobre o impacto ambiental dos meios de obtenção energética. Perguntas como: o que são energias renováveis e porquê devemos usá-las? Por que a energia solar se destaca como uma energia renovável menos incisiva ao meio ambiente do que a energia hidrelétrica, que é a mais utilizada no Brasil?

A segunda proposta está relacionada com a produção de um quadro-cartaz, onde se destacam os principais tipos de células fotovoltaicas para conversão de energia solar em energia elétrica. O objetivo é fazer o aluno pesquisar essas diferentes alternativas, para que construa uma opinião crítica que possa expor em forma de seminário.

Os alunos são incentivados a pesquisar não somente informações técnicas, mas também àquelas de utilidade para práticas sustentáveis. O item "repercussão ambiental" pode estar relacionado com as formas e os custos com o descarte de poluentes.

A terceira proposta consiste em um miniprojeto sustentável, onde o aluno planeja um sistema fotovoltaico capaz de suprir as necessidades energéticas da sua própria casa. Esse projeto é confeccionado a partir dos dados elétricos mensurados no protótipo de célula solar sensibilizada com extratos de plantas e das informações obtidas pela simulação computacional do software Scilab 5.1.1. Um fluxograma na figura 7 mostra todas as etapas para a confecção do projeto.

Após receberem explicações sobre o funcionamento e montagem da célula solar, os alunos são direcionados a bancadas onde há todos os componentes. Eles recebem orientação de um professor para efetuar a etapa da montagem da célula solar. Em seguida são feitos testes sob a luz solar, onde os dados elétricos são coletados com um multímetro (ou multiteste) por um tempo específico. Esses dados elétricos podem ser tratados de acordo com o nível de escolaridade dos alunos, indo desde de médias aritméticas simples à um tratamento estatístico mais elaborado. Assim, o próximo passo é a inserção desses dados no software simulador.

O software Scilab 5.1.1 resolve as equações físicas do modelo da célula solar (modelo de diodo) a partir dos dados elétricos mensurados e tratados. Esse software efetua a reiteração dos cálculos sendo capaz de plotar os gráficos característicos e estimar a quantidade de energia gerada durante os testes. Uma simples comparação dessa energia obtida com a quantidade consumida em uma residência (conta de luz) pode determinar a quantidade dessas células para o consumo mensal. Por fim, o último tópico se relaciona com a vantagem sustentável desse projeto.

O último tópico do projeto é relacionado diretamente com a educação ambiental, pois consiste em uma reflexão comparativa sobre as diferentes formas de aquisição de energia. Essa comparação pode mostrar a superioridade na diminuição dos impactos ambientais da energia solar em relação a fontes de energia poluentes, como a queima de combustíveis fósseis. Assim, essas propostas podem ser utilizadas em sala de aula para promover a educação ambiental através da simulação de células solares. 


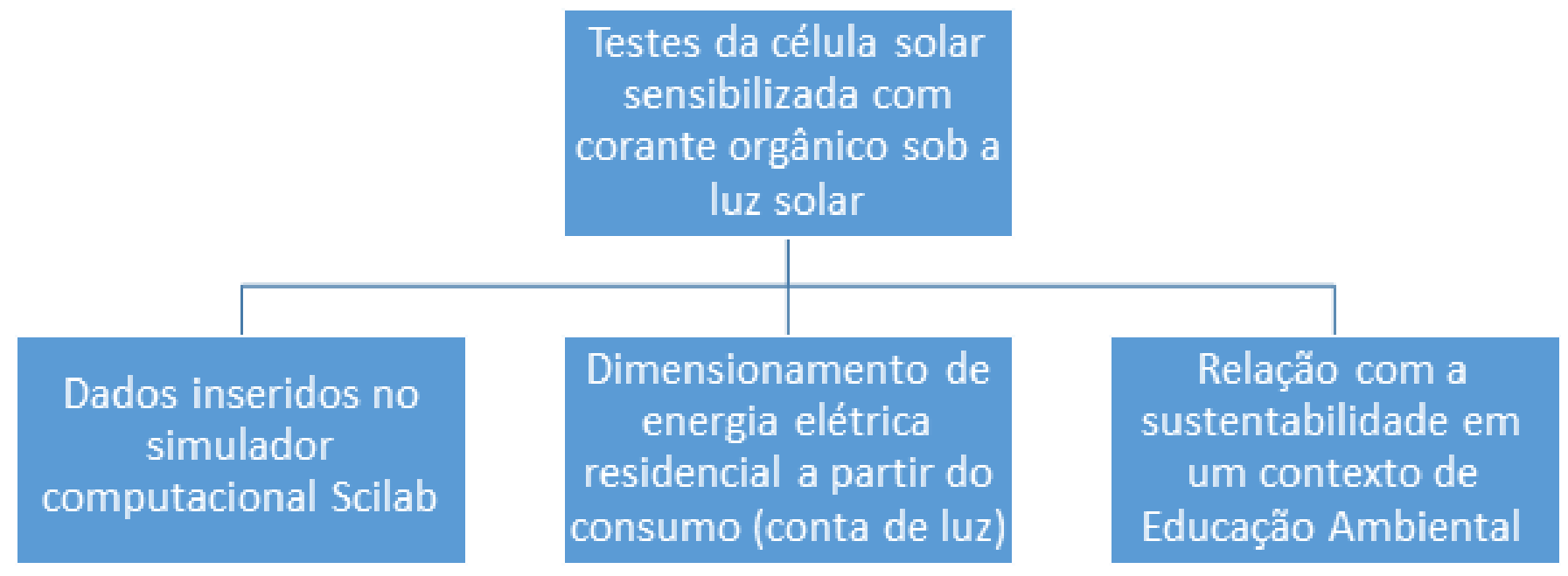

Figura 7 - Fluxograma do miniprojeto sustentável

\section{Conclusões}

Neste trabalho foi desenvolvido uma metodologia para trabalhar a educação ambiental utilizando simulação de dados de células solares. Para que tenha resultado satisfatório, ao iniciar esse projeto, o aluno deve ter um conhecimento prévio sobre o assunto e esse conhecimento pode ser adquirido a partir de pesquisas, seminários e debates na própria sala de aula. Com a montagem e caracterização da célula através de simulação o aluno é apto a elaborar um miniprojeto de dimensionamento de quantas células solares seriam necessárias para suprir a demanda de sua residência. Desta forma, o aluno tornouse crítico e reflexivo mediante esse assunto.

Os dados mostram que os resultados obtidos utilizando simulador solar e simulado no software Scilab 5.5.1 são muito próximos mesmo quando se utilizam solventes extratores distintos. Nenhuma simulação das características elétricas teve erro relativo maior que $20 \%$. Assim, as duas simulações apresentaram curvas $\mathrm{I}-\mathrm{V}$ aproximadas que descrevem de forma satisfatória o comportamento das propriedades elétricas da célula solar sensibiliza com corante orgânico.

Observou-se que o software Scilab 5.5.1 pode ser usado para descrever, representar, analisar o modelo da célula solar para um melhor entendimento no ensino sobre o funcionamento sobre células solares. Verificou-se sua utilidade para a descrição das propriedades elétricas da célula solar sensibilizada com corante em forma de uma matriz de valores e a produção da curva de diodo tanto de forma analítica como gráfica. Isso mostra que a simulação com esse software, usando suas funções e comandos, pode ser utilizada para supor modelos fotovoltaicos, descreve-los e analisá-los com uma boa aproximação dos valores reais.

Portanto, o estudo de parâmetros fotovoltaicos por simulação em softwares livres, ou "open source", se apresenta como uma ferramenta viável e de baixo custo para o maior desenvolvimento de uma Educação Ambiental voltada para a energia solar. Essa viabilidade permite a expansão desse estudo para diversos setores na educação, sobretudo a escola pública.

\section{Agradecimentos}

Os autores agradecem a CAPES pelo apoio financeiro.

\section{Referências}

AGÊNCIA NACIONAL DE ENERGIA ELÉTRICA. Atlas de energia elétrica do Brasil. Brasília. ANEEL, 236 p. 2008.

AGNALDO, J. S.; CRESSONI, J. C. Células solares de TiO2 sensibilizado por corante. P. 77-84, 2006.

AMANTÉA, R. P. Algoritmos e lógica de programação práticas de laboratório 2014/2. Centro universitário UNA. Instituto politécnico. v.1, 2014.

BALRAJU, P. SERESH, M. KUMAR, M. S. ROY, G. D. SHARMA, J. Effect of counter electrode, thickness and sintering temperature of $\mathrm{TiO} 2$ electrode and TBP addition in electrolyte on photovoltaic performance of dye sensitized solar cell using pyronine G (PYR) dye Photochem. Photobio. A 206 (2009) 53-63. 
BRASIL. Ministério da Educação (MEC), Secretaria de Educação Média e Tecnológica (Semtec). PCN + Ensino médio: orientações educacionais complementares aos Parâmetros Curriculares Nacionais - Ciências da Natureza, Matemática e suas Tecnologias. Brasília: MEC/ Semtec, 2002.

CHANG, H.; WU, H. M.; CHEN, T. L.; HUANG, K. D.; JWO, C. S.; LO, Y. J. Dye-sensitized solar cell using natural dyes extracted from spinach and ipomoea. Journal of Alloys and Compounds, 2010.

COSTA, S. V. Construção de Células Solares Sensibilizadas por Corante a partir de Nanoestruturas de ZnO obtidas por Método Hidrotermal. 2011. 124f. Dissertação (Mestrado em energia) - Universidade Federal do ABC, Santo André, 2011.

DYE SOLAR CELL. Nanocristaline - Dye Solar Cell Lab. Disponível em: http://photonicswiki.org/index. php?title=Nanocrystalline_-_Dye_Solar_Cell_Lab. Acesso em: 19/06/2016.

EFFTING, T. R. Educação Ambiental nas Escolas Públicas: Realidade e Desafios. Marechal Cândido Rondon. 2007. Monografia (Especialização em Planejamento Para o Desenvolvimento Sustentável) - Centro de Ciências Agrárias, Universidade Estadual do Oeste do Paraná, Rondon, 2007.

EDUCAÇÃO, Ministério da. Educação Ambiental: Aprendizes da Sustentabilidade. Caderno Secad 1. Brasília, 2007.

FARIAS, J. Simulação de células solares fotovoltaicas usand o o software NI MULTISIM. Congresso brasileiro de educação em Engenharia. Gramado, RS. 2013.

FEITOSA, A. V.; Estudo de novos corantes naturais fotoexcitáveis como sensibilizadores em células solares. 2011. 113 f. Dissertação (Mestrado em ciências físicas aplicadas), Universidade Federal do Ceará. Fortaleza, 2011.

GOMES, D. V. Educação para o consumo ético e sustentável. Rev. eletrônica Mestr. Educ. Ambient., v.16, p. 18-31, jan/ jun, 2006.

GHENSEV, A. Materiais e processos de fabricação de células fotovoltaicas. 2006. 154 f. Monografia (Especialização em Fontes Alternativas de Energia) Universidade Federal de Lavras, Minas Gerais, 2006.

GRÄTZEL, M. Conversion of sunlight to eletric power by nanocrystaline dye-sensitized solar cells. J. Photochem. Photobiol. A: Chem, v. 164, p.3, 2004.
GREIS, L. k.; REATEGUI, e. Um simulador educacional para disciplina de física. Novas tecnologias na educação, v. 8, n. 2 , p. 38, 2010.

GREIS, L. Um simulador educacional para disciplina de física em um mundo virtual. CINTED-UFRGS. Novas Tecnologias na Educação, v. 8, n. 2, julho, 2010.

HAO, S., WU, J., HUANG, Y., LIN, J. Natural dyes as photosensitizers for dye-sensitized solar cell. Solar Energy, v. 80, p. 209, 2005.

MARTINS, F. R.; ABREU, S. L.; RÜTHER, R. Atlas brasileiro de energia solar. São José Dos Campos: INPE, 2006, 60 p.

MEDICINAIS, As plantas. Espirradeira-Nerium oleander. Disponível em: http://www.asplantasmedicinais. com/espirradeira-nerium-oleander.html. Acesso em: 08/05/2016.

NOGUEIRA, A. F. Células solares de Grätzel com eletrólito polimérico. 2001. 171 f. Tese (Doutorado em Química) Universidade Estadual de Campinas, Campinas, 2001.

O'REAGAN, B.; GRATZEL, M. A low-cost, high-efficiency solar cell based on dye-sensitized colloidal films. Nature, v. 353, p. 737-740, 1991.

PATROCÍNIO, A. O.; ILHA, M. N. Em busca da sustentabilidade: células solares sensibilizadas com extratos naturais. Quim. Nova, Vol. 33, No. 3, 574-578, 2010.

SAELIM, Ni-on.TiO2 modified natural clay semiconductor as a potencial electrode for natural dye-sensitized solar cell. Ceramics International 37 (2011) 659-663.

SANTOS, J.A.; MICHELS, R.N. Modelagem matemática de um painel fotovoltaico no software Scilab. Revista eletrônica de tecnologia e cultura - RETC, Edição 11ª v. 3, p. 28, 2012.

SILVA, R. et al; Células solares "caseiras". Revista Brasileira de Ensino de Física, v. 26, n. 4, p. 379 - 384, (2004).

SAMPAIO, S.G. Estudo e caracterização de novos corantes naturais para células solares sensibilizadas. 2013. 96 f. Dissertação (Mestrado em Engenharia Mecânica). Universidade Federal do Ceará, Fortaleza, 2013.

YAMAZAKI, E.; MURAYAMA, M.; NISHIKAWA, N.; HASHIMOTO, N.; SHOYAMA, M.; KURITA, O. Utilization of natural carotenoids as photosensitizers for dye-sensitized solar cells. Solar Energy, v. 81, p. 512-516, 2007. 